\title{
The energy efficient lighting in kindergartens
}

\author{
Alexandra Gulbinas ${ }^{1, *}$, Vera Petuhova $^{1}$ \\ ${ }^{1}$ Russia, Tyumen, Tyumen Industrial University, Volodarskogo str., 38
}

\begin{abstract}
The article discusses the results of a survey of the light environment parameters in preschool educational institutions in Russia. Improving the light environment means, on the one hand, maintaining the quality of lighting, and on the other hand, improving energy efficiency and thereby reducing the financial burden. The first step in improving energy efficiency can be called an energy audit of educational institutions and the development of economically viable measures to save energy. The energy efficiency indicator was put in the first place, and to some extent the quality indicators of lighting were forgotten (for example, such as color rendition, color temperature, uniformity of illumination and etc). During the survey of the light environment, we made disappointing conclusions about the inconsistency with the parameters of regulatory documents. The lack of visible results of the implementation of energy-based solutions makes the kindergarten's management adhere to standard solutions for improving efficiency and not worrying about the quality of lighting. It is necessary to comprehensively consider the issues of improving the light environment and take into account not only the energy efficiency, but also the quality indicators of lighting systems. In turn, the number of indicators of energy efficiency of buildings must be expanded.
\end{abstract}

\section{Introduction}

Improving the energy efficiency of buildings is one of the strategies formulated by the international community in order to reduce greenhouse gas emissions [1]. According to the calculations of the European Commission [2], the amount of energy consumption by buildings and structures can be reduced by using cost-effective measures. Among the budgetary municipal organizations in Russia, large consumers of energy are pre-school educational institutions. The costs of artificial lighting are significant. It is for public facilities that have budgetary participation in financing, according to Russian Federal Law No. 261 On Energy Saving and Improving Energy Efficiency, measures aimed at increasing energy efficiency are necessary. So, in 2010-2012 the first energy survey was conducted and it indicated some measures to improve the efficiency in buildings of the budget sector. Currently, the settlement and explanatory notes to the energy passport and the energy passports themselves have not become important or necessary documents for heads and directors of institutions [3].

Well-lit rooms have an enormous living and working comfort Meaning. Because people spend their time mostly in the building. Daylight respectively good artificial light increase

* Corresponding author: gulbinasa@mail.ru 
well-being and concentration. With efficient lighting can be, compared to conventional installations, saving 80 percent of the electricity consumption. This effect is possible without loss of visual comfort. However, this requires current knowledge, precise planning and a careful selection of all components, so the lamps, ballasts and luminaires, as well as of control and regulation components. The challenge for heads and directors of institutions is to combine high quality illumination with a low electricity demand.

When designing a comfortable light environment and choosing lighting equipment, such characteristics as the level of illumination, uniformity, brightness, color temperature, color rendition, maximum allowable specific installed power should be taken into account. With the current level of practice and regulatory documentation, it can be said that the optimal light environment is the observance of the quantitative and qualitative characteristics necessary to achieve optimal visual performance and visual comfort, taking into account the optimization of energy efficiency and the convenience of lighting systems in use.

Now the country has introduced restrictions on the use of lamps with low color rendering in industrial, educational and commercial premises. The parameters of specific installed power $(\mathrm{W} / \mathrm{m})$ in the rooms are being tightened, depending on the shape and purpose of the premises. The use of LED light sources is permitted with restrictions, for example, the use of LED light sources is not allowed in preschool educational institutions and in children's clinics.

\subsection{Projected parameters of the light environment in kindergarteners}

The main premises of kindergartens are group or play rooms. For such premises and the organization of lighting can be identified a number of necessary requirements on the basis of recommendation Russian Standard, for example the Code of Practice - SP 52.13330.2016 SniP Natural and artificial lighting (hereinafter referred to as SP), Sanitary rules and regulations SanPiN 2.4.1.3049-13. "Sanitary and epidemiological requirements for the arrangement, content and organization of the mode of operation of preschool educational organizations" (with changes as of August 27, 2015) (hereinafter SanPin) and State standard GOST R 55710-2013 "Lighting of workplaces inside buildings. Norms and methods of measurement" (hereinafter GOST) in Russia:

- Group or play rooms - these are rooms of public buildings with normal environmental conditions; category and subdivision of visual work - A-2

- Balanced daylight milieu by day. The coefficient of natural light in the design point at a distance of $1 \mathrm{~m}$ from the outermost wall must be more than 1:5

- Windows should face east, south, or west

- The number of cleanings of the glass aperture glazing - at least one time per year

- The number of lighting fixtures - at least two times a year

- Height of the normalization plane - $0.0 \mathrm{~m}$ (at the floor level)

- Lighting devices in rooms for children must have protective light-diffusing fittings

- Sources of artificial lighting should provide sufficient uniform illumination of all rooms

- Placing fixtures - along the light-bearing wall

- Finishing materials and paints of soft tones are used in the rooms.

Artificial lighting is designed in accordance with current rules and regulations, and such characteristics as the level of illumination, uniformity of distribution, brightness, color temperature, color rendering, etc., should be taken into account. So, for example, the calculation of lighting, the choice of lighting equipment and light sources in the design of kindergarten rooms is carried out according to the parameters given in Table 1. 
Table 1. Parameters of the light environment in preschool educational institutions

\begin{tabular}{|c|c|c|c|}
\hline Parameter & Value & $\begin{array}{c}\text { Russian } \\
\text { Standard }\end{array}$ & Note \\
\hline $\begin{array}{l}\text { Color temperature } \\
\text { range }\end{array}$ & $3500-5500 \mathrm{~K}$ & $\begin{array}{l}\text { SP, appendix K } \\
\text { (recommended) }\end{array}$ & $\begin{array}{l}\text { In the room when } \\
\text { performing visual works } \\
\mathrm{AB} \text { and illumination from } \\
300-500 \text { lux }\end{array}$ \\
\hline $\begin{array}{l}\text { The color rendering } \\
\text { index of light sources }\end{array}$ & $\begin{array}{l}\text { The first value is } \\
80-84 ; \quad \text { second } \\
\text { value } 80\end{array}$ & $\begin{array}{l}\text { SP, the first } \\
\text { value is } \\
\text { appendix K } \\
\text { (recommended) } \\
\text { SP, the second } \\
\text { value - appendix } \\
\text { L (mandatory) }\end{array}$ & $\begin{array}{l}\text { In the room when } \\
\text { performing visual works } \\
\text { AB and illumination from } \\
300-500 \text { lux }\end{array}$ \\
\hline Light source & $\begin{array}{l}840,865 \text { ("lamps } \\
\text { of natural light } \\
\text { with high-quality } \\
\text { color rendering") }\end{array}$ & $\begin{array}{l}\text { SP, appendix K } \\
\text { (recommended) }\end{array}$ & $\begin{array}{l}\text { The use of LED light } \\
\text { sources is not allowed in } \\
\text { pre-school educational } \\
\text { institutions, clause 7.3.1, } \\
\text { SP }\end{array}$ \\
\hline $\begin{array}{l}\text { Maximum } \\
\text { specific installed } \\
\text { power }\end{array}$ & $\begin{array}{l}\text { From } 12 \text { to } 20 \mathrm{~W} / \\
\text { sq.m depending on } \\
\text { the index of the } \\
\text { room }\end{array}$ & $\begin{array}{l}\text { SP, appendix L } \\
\text { (mandatory) }\end{array}$ & $\begin{array}{l}\text { When illuminated on a } \\
\text { horizontal surface }\end{array}$ \\
\hline $\begin{array}{l}\text { Level of illumination } \\
\text { (Group, playing), } E_{m}\end{array}$ & $400 \operatorname{lux}$ & $\begin{array}{l}\text { GOST, } \\
\text { appendix K } \\
\text { (mandatory) }\end{array}$ & $\begin{array}{l}\text { At the level of the floor G- } \\
0,0 \mathrm{~m}\end{array}$ \\
\hline $\begin{array}{l}\text { Uniformity }\left(\mathrm{U}=\mathrm{E}_{\min } /\right. \\
\left.\mathrm{E}_{\max }\right)\end{array}$ & not less than 0.40 & SanPin & - \\
\hline $\begin{array}{l}\text { Operational } \\
\text { illumination (the } \\
\text { minimum allowable } \\
\text { value of the average } \\
\text { illumination during } \\
\text { the entire time of } \\
\text { operation of the } \\
\text { lightning sources) }\end{array}$ & $300 \operatorname{lux}$ & SanPin, table 34 & $\begin{array}{l}\text { The height of the } \\
\text { normalization plane is not } \\
\text { specified }\end{array}$ \\
\hline
\end{tabular}

\subsection{Control of the light environment parameters}

The role of artificial lighting increases in the short winter days. On average, in winter, a child spends about 10 hours a day only in an educational institution for children in a room with the lights on, under the influence of artificial rays of light sources. The indisputable fact is the effect of artificial lighting on the eyes of man, and especially children. Under adverse conditions of the light environment, the risks of early visual impairment and well-being increase [4-7]. It is possible to take into account the prevention of the negative effects of artificial light and the reduction of the child's visual and general fatigue in the room, while observing the normalized parameters of the light environment in the rooms (Table 1).

In turn, monitoring and evaluation of the light environment in the premises of the longused buildings are carried out mainly in terms of the level of illumination at the points of the minimum value on the working surface in accordance with SanPiN indicators. Other standardized indicators presented in Table 1 within the framework of conducting surveys (for example, when conducting an energy survey (Order No. 400 of Ministry of Energy of the Russian Federation Approving the requirements for conducting an energy survey, 2016), 
when conducting a special assessment of working conditions (Order No 33n of Ministry of Labor and Social Protection of the Russian Federation On approval of the methodology for conducting a special assessment of working conditions, 2014)) are not checked.

Over the course of time, a lighting installation operated in a room can be (even unconsciously) changed by the operating organization with respect to the initial design parameters. In the absence of an appropriate specialist in the organization, the wrong equipment or components may be purchased: for example, changing a lamp in a lighting installation to a lamp of lower cost, but with unsuitable color rendering or color temperature parameters leads to a deterioration of the light environment.

\section{The results of the evaluation of the light environment parameters}

Evaluation of the effectiveness and quality of the light environment in kindergartens was carried out on the basis of a survey of housekeeping institutions, inspection of kindergarten premises, the study of energy passports and explanatory notes (reports) to energy passports, efficiency declarations, technical passports for preschool buildings and measurements in standard buildings. The methodology of the survey was based on the method $[8,9]$. After assessing the light environment parameters in the selected preschool educational institutions in Tyumen city (Figure 1), it was concluded that none of the institutions fully comply with all the regulatory parameters for the quality of the light environment shown in Table 1. And if the level of illumination in group kindergarten rooms basically corresponds to the normalized parameters, the quality characteristics of the light sources do not meet the relevant requirements. In other regions of the country, there is also a discrepancy between the level of artificial illumination and regulatory requirements.

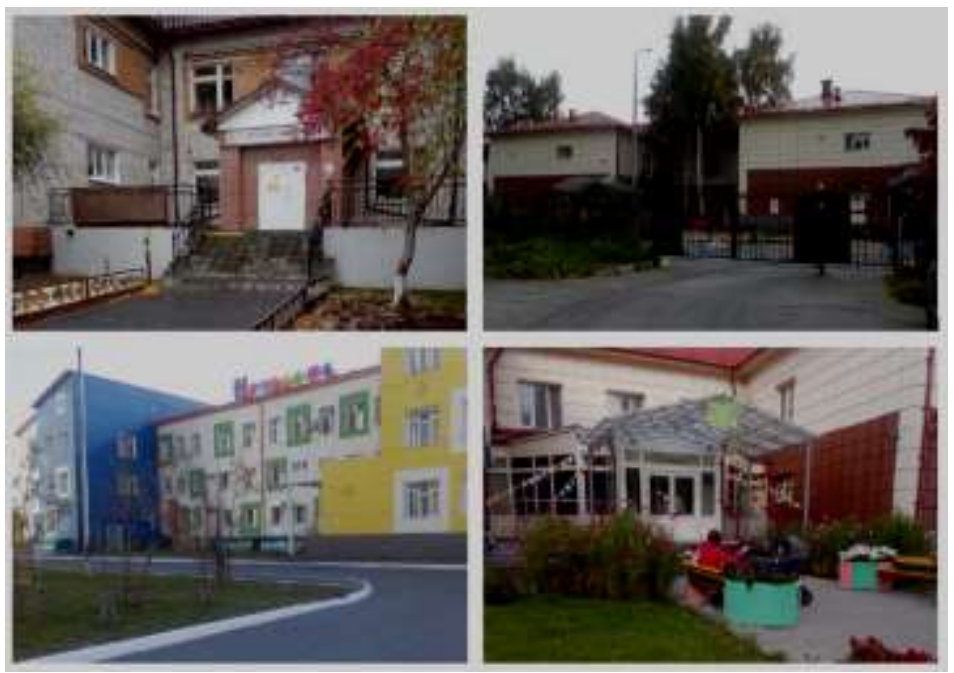

Fig. 1. Preschool institutions of Tyumen.

Also it was noted during the survey that currently a partial repair of the premises is underway in many preschool organizations, including the replacement of lighting equipment. The replacement and selection of fixtures is carried out on the basis, including recommendations of colleagues, designers and electricians. So we noted that there takes place precisely the replacement of incandescent lamps and linear fluorescent lamps for internal lighting on LED light sources in group rooms of the kindergarten. Although this case does 
not comply with the requirements of regulatory documents (clause 7.3.1, SP), the replacement of lighting equipment and light sources with non-compliant regulatory documents is being carried out. Also, in personal communication with kindergarten managers, it was noticed that in kindergartens they do not have information about banning the use of LED light sources in the premises of preschool educational institutions.

Based on the data of energy passports in the premises of kindergartens, the average values of specific electricity consumption for the needs of lighting in the city of Tyumen were identified (Figure 2). In 2010-2011, the specific consumption in kindergarten buildings was significantly higher than in 2015-2016, including in connection with the use of incandescent lamps. After the first energy surveys (exactly in 2010-2011), incandescent bulbs were replaced with compact-luminescent bulbs everywhere. The use of specific energy consumption values and a number of other indicators given in Table 2 reveal a new potential for energy saving and a desire for the lowest consumption [10-11].

It should be noted that figure 2 shows the generalized average indicators, though the practical interest for heads of kindergartens, as managers, is not caused by the average consumption in the city, but rather the smallest and largest specific values. Low specific values in one of the institutions are a demo for others. High rates indicate the need for not only organizational and low-cost activities, but most likely for the reconstruction of the lighting system as a whole.

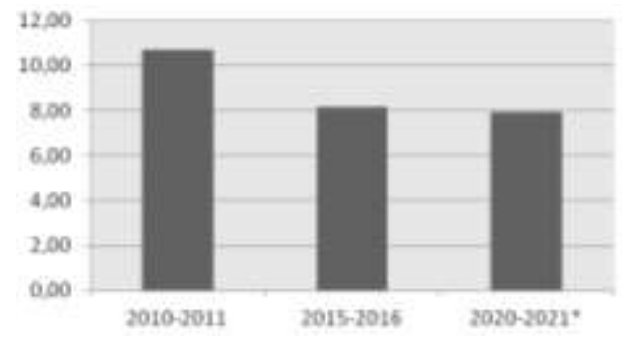

Fig. 2. Specific energy consumption (kWh/sq.m), * - the expected reduction in specific energy consumption during the transition to lighting automation systems.

Conclusions after the examination of pre-school educational institutions of Tyumen:

- In kindergartens, there is no metering device for electricity consumption for lighting purposes.

- It is impossible to determine the electricity consumption correctly for the base year due to the lack of reliable data in institutions.

- Annual inventory of lighting equipment and lamps with indication of characteristics in institutions is not carried out.

- The average working time of kindergartens is different, and the calculation of total electricity consumption is based on averaged values, rather than on a specific institution and working time characteristics.

- The obligation to organize and conduct follow-up energy audits after the first one is not performed at least once every five years.

- Annually, the staff of the institutions electronically fill in the efficiency declaration;

- The declaration of efficiency within the framework of efficiency and quality control of the light environment is formal and not informative.

- The staff of kindergartens does not have information about modern methods of energy saving, and is not motivated by behavioral energy saving.

- Purchase, replacement of light sources is mainly carried out by external workers, the quality parameters of the replaced light sources are not controlled. 


\section{Recommended measures to improve the light environment}

For compliance of light characteristics and quality of the light environment with regulatory requirements in the premises of kindergartens, an integrated approach is proposed [8]. This approach should ensure the preservation of health and a comfortable stay of children attending kindergarten, with effective use of lighting equipment and compliance with qualitative and quantitative lighting characteristics in the room with the increasing role of the aesthetic characteristics of the appearance of equipment. Such methods of implementation exist in the world, for example in $[8,12,13]$.

For the analysis of the light environment of kindergarten rooms, it is necessary to summarize the following source data for each building of a preschool institution:

- type and number of existing lighting fixtures;

- type, quantity and power of used lamps;

- number of hours of operation of the artificial lighting system;

- the number of cleanings of lighting fixtures;

- actual and normalized light level;

- values of the mains voltage of the lighting at the beginning and at the end of the light measurement;

- dimensions of the room (area), including the total heated area, the area of the main and auxiliary premises;

- the number of children attending kindergarten;

- the number of working personnel and features of the mode of operation;

- average actual service life of used light sources and additional equipment.

For the introduction of an integrated approach to quality control of the light environment, additional measures are proposed aimed at working not only with the initial data of the institution, but also with the kindergarten personnel and determining the necessary indicators:

1. Monthly diagnostics of lighting equipment: Testing the operability of light sources with logging.

2. Compiling a register of purchased light sources and additional equipment for lighting installations with an indication of the required quality characteristics, compiled on the basis of current regulatory and legal documentation and lighting project. The amount of time needed to replace light sources or additional equipment. The cost of maintenance of lighting devices.

3. Conducting a team survey about staff actions in familiar situations in order to draw attention to the problem of energy saving and in an unobtrusive form indicate possible additional energy saving measures $[14,15]$.

4. Diagnostics: analysis of the monthly diagnostics log with the identification of lighting equipment, most often under maintenance; annual self-examination and determination of specific power consumption values (table 2 ).

The design of smart buildings today is aimed at providing a safe, healthy, comfortable, affordable and beautiful and energy-saving space. The use of specific and reduced consumption values in an integrated approach to improving the efficiency of the light environment makes it possible to estimate the energy consumption in the whole building, in a separate room or for different periods of time.

Table 2. The values of power consumption for monitoring the efficiency of the light environment in the premises of kindergartens.

\begin{tabular}{|c|c|}
\hline Value & Note \\
\hline Total installed power of lighting equipment, $\mathrm{kW}$ & $\begin{array}{c}\text { Determined within the } \\
\text { framework of energy } \\
\text { audit once in 5 years }\end{array}$ \\
\hline
\end{tabular}




\begin{tabular}{|l|c|}
\hline $\begin{array}{l}\text { Specific energy consumption for lighting needs per 1 sq.m of } \\
\text { building area per year, (kWh / sq.m) }\end{array}$ & Not determined \\
\hline $\begin{array}{l}\text { Specific energy consumption for the needs of lighting in the main } \\
\text { premises (W / sq.m) }\end{array}$ & Not determined \\
\hline $\begin{array}{l}\text { The reduced specific installed power of the main rooms (W / sq.m } \\
100 \text { lux) }\end{array}$ & Not determined \\
\hline $\begin{array}{l}\text { Specific energy consumption for the needs of lighting per child per } \\
\text { year (kWh / pc.) }\end{array}$ & Not determined \\
\hline
\end{tabular}

\section{Conclusions}

A comprehensive approach to monitoring the quality of the light environment offered for implementation in preschool educational institutions will allow institutions to independently compare and evaluate energy consumption indicators, plan and organize energy efficiency measures, monitor the quality of the light environment of the premises, and learn how to motivate the staff of the institution to use energy-saving methods and new technologies, like using smart home technology or biodynamic lighting.

In turn, the obtained data on the specific values of electricity consumption for lighting needs make it possible to monitor the energy efficiency of lighting systems in buildings. On the basis of specific power consumption, it is possible to compare the power consumption of the lighting systems of different preschool educational institutions in one city, region, and the country as a whole, depending on the area of the building, area of the room, or depending on the number of children attending the kindergarten. The results of the monitoring will serve as a basis for developing recommendations for improving the efficiency of electricity consumption for lighting and a possible reduction of the financial burden in a preschool institution.

\section{References}

1. IEA, Energy Efficiency Market Report 2016 (2016)

2. European Commission, Energy Efficiency Plan 2011 (2011)

3. S.Yu. Shuvalov, Energy Service Contracts in Budget Sector Objects, Problems and Solutions, Energy Saving, 12-15 (2018)

4. D. Slayni, Influence of new lighting equipment on health and safety of people, Light \& Engineering, 49-50 (2010)

5. V.N. Deinego, Prevention of ocular diseases in children and teenager in classrooms with led light sources of the first generation, Russian ophthalmology of children, 57-72 (2016)

6. V.N. Deinego, Energy saving and led lamp lighting and human health. Gigiena i sanitariia, 81-84 (2013)

7. P.P. Zak, The potential danger of illumination by LEDs for the eyes of children and teenagers. Lighting, 4-6 (2012)

8. S. Gasser, D. Tschudy, Gutes Licht, Faktor Verlag ,117-134 (2012)

9. S. Gasser, Oerlikon Journalisten AG, 4-13 (2011)

10. R. Jia, Proceedings of the IEEE 106, 1680-1699 (2018)

11. A.B. Loskutov, The method of calculating energy savings in existing lighting installations of premises during an energy audit, https://ecoteco.ru/id174 
12. M. Lalošević, M. Komatina, M. Miloš, Facta Universitatis. Series: Architecture and Civil Engineering, 415-430 (2017).

13. M.M. Josijevic, Thermal science 21, 2931-2943 (2017)

14. A. Gulbinas, Science and Technologies of the XXI century: opportunities and risks, 62 64 (2017)

15. A. Gulbinas, Scientific and Practical Conference 'Actual Problems of Construction, Ecology and Energy Conservation in Western Siberia', 92-96 (2014) 